\title{
KAJIAN 'URF PADA PENOLAKAN SERTIFIKASI HALAL MUI TERHADAP PENAMAAN PRODUK BERLABEL SETAN
}

\author{
Siti Nur Faiza \\ Universitas Islam Negeri Sunan Ampel Surabaya \\ e-mail: Faizahafidzah@gmail.com
}

\begin{abstract}
Abstrak
This research is the result of field research to analyze the 'urf study on the rejection of the MUI halal certification of naming "devil noodle products". In conducting research, the author uses qualitative methods by using field data and complemented by secondary data to strengthen the analysis that comes from previous research, books, journals, decrees, and others. Then, uses descriptive analysis techniques to analyse. Noodle devil is one of the spicy culinary foods that has a lot of customers but in its business journey this product did not get approval to get the halal label of the East Java MUI because the devil's name does not match "SK 46 / Dir / LPPOM MUI / XII / 14 and Fatwa MUI Number. 4 of 2003 concerning Standardization of Halal Fatwa. "Although the devil noodle product has been known to mean spicy noodles with a level of spiciness, the custom of using the name devil includes urf 'lafzi which is unacceptable because the word devil is included in the category of names of Allah's enemies who are feared to keep them from remembering Allah. Based on the validity of the 'urf naming' of products labeled satanic, including 'urf fasid' which must be abandoned. From the results of the research, LP POM MUI East Java is very careful in accepting or rejecting applications for Halal Product Certification, the first step of the East Java LPPOM MUI is to assess the name or symbol on the product being proposed. If Surabaya devil noodle sellers want to get the halal label from the East Java MUI, they must change the devil's name to a good name and symbol that not lead to kufr and forget to remember Allah.
\end{abstract}

Keywords: Rejection of MUI halal certification, Devil noodle products, 'Urf.

\section{A. PENDAHULUAN}

\section{Latar Belakang Penelitian}

Dalam dunia bisnis, banyak pengusaha mencari ide baru untuk menjadikan produknya menarik dan banyak pembeli, seperti memberi nama unik dan menarik pada produk sehingga dapat membuat konsumen penasaran dengan produk tersebut, misalnya penggunaan nama setan pada produk rawon setan, mie setan, ceker setan, makaroni setan dan sebagainya. Mie setan merupakan salah satu bisnis kuliner yang terkenal dan digemari oleh pecinta pedas di Surabaya. Penggunaan nama setan memberikan kesan unik dan memiliki makna pedas pada produk yang ditawarkan, hingga akhir ini mie setan tetap menjadi salah satu usaha yang memberikan keuntungan menjanjikan karena karena memiliki banyak pelanggan dan memiliki cabang di beberapa kota, seperti Malang, Surabaya, Bali, dan daerah lainnya. 
Untuk menjamin makanan maupun produk yang dijual halal maka adanya pemberian label halal MUI pada produk memberikan jaminan halal melalui penelitian dan audit yang dilakukan oleh pihak LP POM MUI Jatim dan komisi fatwa untuk mengeluarkan sertifikasi halal MUI pada produk tersebut. Pemberian sertifikat halal MUI bersifat suka rela, maksudnya hanya produk yang didaftarkan ke LP POM MUI yang akan mendapatkan kesempatan untuk diteliti hingga mendapatkan sertifikasi label halal MUI Jatim. ${ }^{1}$ Pada tahun 2016 karena banyaknya pertanyaan dari konsumen mie setan tentang kehalalan produknya, maka investor mie setan yang bernama Runiar beriktikad baik untuk menjamin kehalalan produk mie setan, akan tetapi pengajuan sertifikasi label halal tidak diterima hingga pihak mie setan menganti nama produk dengan nama lain yang baik. ${ }^{2}$

Adapun pertimbangan LP POM MUI melakukan Penolakan pengajuan sertifikasi halal MUI pada produk mie setan. Pertama, Fatwa MUI Nomor 4 Tahun 2003 Tentang Standarisasi Fatwa Halal pada bagian ke empat poin pertama mengenai penggunaan nama dan bahan menyebutkan "tidak boleh mengkonsumsi dan menggunakan nama dan atau simbolsimbol makanan atau minuman yang mengarah kepada kekufuran dan kebatilan."3

Kemudian berdasarkan Surat Keputusan 46/Dir/LPPOM MUI/XII/14 pada poin ke tiga yang mengatur nama produk yang tidak disertifikasi, yaitu "Nama produk yang mengandung nama

\footnotetext{
${ }^{1}$ Ma'ruf Amin. Dkk, Himpunan Fatwa Majelis Ulama Indonesia Sejak 1975 (Jakarta: Erlangga, 2011), 916.

${ }^{2}$ Runiar, Wawancara (Surabaya, 2018).

${ }^{3}$ MUI, 'Standardisasi Fatwa Halal', Himpunan Fatwa MUI, 2003, 1-4.
}

setan, seperti rawon setan, es pocong, mie ayam kuntilanak."

Meskipun penggunaan nama setan telah menjadi kebiasaan di masyarakat memiliki makna makanan pedas. Dalam kehidupan masyarakat banyak kebiasaan atau tradisi yang popular dilakukan, baik perkataan atau perbuatan yang berlaku umum dalam masyarakat. Akan tetapi, tidak semua kebiasaan masyarakat dapat dijadikan 'urf, karena hanya 'urf shahih saja yang dapat dijadikan hukum. Penggunaan nama setan akan menjadi pembahasan pada penelitian ini, yang menarik adalah kata setan yang telah memiliki popularitas di masyarakat memiliki makna makanan pedas, akan tetapi pihak LP POM MUI Jatim menolak pengajuan sertifikasi halal MUI dikarenakan namanya setan. Dari latar belakang tersebut, penulis tertarik untuk melakukan kajian urf terhadap penolakan sertifikasi halal MUI pada produk mie setan.

\section{B. METODE PENELITIAN}

Jenis Penelitian artikel ini menggunakan jenis penelitian kualitatif dengan melakukan penelitian lapangan (field research) yaitu mencari data kepada pemilik usaha mie setan dan pihak LP POM MUI Jatim. Teknik pengumpulan data menggunakan observasi dengan melihat langsung suasana dan kondisi di tempat usaha mie setan, wawancara kepada direktur dan seorang staf LP POM MUI Jatim, pemilik usaha mie setan, dan dokumentasi.

Dalam penelitian artikel ini sumber data primer diperoleh dari wawancara langsung kepada pemilik usaha mie setan dan pihak LP POM MUI Jatim, kemudian sumber data sekunder diperoleh dari data yang telah ada, yaitu Fatwa MUI, Surat

\footnotetext{
${ }^{4}$ Majelis Ulama Indonesia, 'Ketentuan Penulisan Nama Produk Dan Bentuk Produk', 2014.
} 
Keputusan LP POM MUI, penelitian terdahulu, buku yang berkaitan tentang 'urf dan media masa. Teknik analisis yang diguanakn adalah analisis deskriptif dengan mendeskripsikan tinjauan 'urf terhadap nama produk mie setan, dengan menggunakan alur berfikir deduktif dengan melakukan analisis hukum islam ('urf) terhadap penolakan sertifikasi label halal MUI yang dijelaskan secara spesifik kemudian ditarik kesimpulan.

Adapun definisi operasional dalam artikel ini: (1) 'Urf adalah adat kebiasaan masyarakat yang popular dan dapat dijadikan sebagai hukum islam, dalam penelitian ini melakukan kajian urf lafzi yang berkaitan dengan bahasa atau pemaknaan yang bersifat umum dan kajian 'urf dari segi keabasahannya; (2) Makna penolakan diartikan sebagai ketidaksetujuan terhadap suatu ide, gagasan, pendapat atau keputusan. LP POM MUI Jatim memiliki kewenangan penolakan terhadap pengajuan sertifikasi halal MUI pada produk yang tidak sesuai dengan kriteria nama produk halal MUI.

\section{Landasan teori}

\section{Pengertian'urf dan adat kebiasaaan}

Adat dan 'urf memiliki arti yang berbeda, menurut bahasa عادة berasal dari kata عاد - يعود yang memiki arti pengulangan. Sedangkan 'urf berasal dari kata 'arafa - yu'rifu (عَرَتَ-يُعِفِن) yang artinya sesuatu yang dikenal. ${ }^{5}$ Dari asal katanya antara adat dan 'urf memiliki kesamaan yakni perbuatan yang dilakukan berulang kali kemudian menjadi terkenal dan diakui banyak orang dan telah menjadi tradisi untuk melaksanakannya atau meninggalkan. ${ }^{6}$ Memang antara' $u r f$ dan adat sekilas memiliki kesamaan makna,

\footnotetext{
5 Totok dan Samsul Munir Amin Jumantoro, Kamus Ilmu Ushul Fiqih (T.tp: Amzah, 2005), 333.

${ }^{6}$ Amir Syarifuddin, Ushul FIqh (Jakarta: Logos Wacana Ilmu, 1997), 364 ..
}

akan tetapi ketika diteliti lebih jauh maka akan ditemukan perbedaan makna antara 'urf dan adat, yaitu:

1. Dalam pengulangan perbuatan atau kebiasaan yang dikategorikan sebagai adat tidak memperhatikan baik atau buruk kebiasaan tersebut. Akan tetapi kebiasaan yang menjadi 'urf memperhatikan nilai kebaikan dalam kebiasaan tersebut. ${ }^{7}$

2. Menurut Siddiqi pengulangan aktivitas secara terus menerus dan membuatnya tertanan dalam hati seseorang maka dalam hal ini adat berganti menjadi 'urf. . $^{\circ}$

3. Menurut Musthafa Syalabi, 'urf diterapkan oleh sekelompok golongan di lingkungan tertentu, sedangkan adat kebiasaan dapat diterapkan perorangan atau sekelompok golongan maupun sebagian golongan.

4. Menurut Mustafa Ahmad Az-Zarqa, 'urf adalah bagian dari adat, akan tetapi tidak semua adat dapat dijadikan ' $u r f$.

Dalan Ensiklopedia hukum Islam 'urf diartikan sebagai segala yang muncul dari pemikiran dan pengalaman mayoritas masyarakat pada daerah tertentu dan berlaku untuk mayoritas masyarakat. ${ }^{10}$ Menurut Wahbah Al-Zuhayli 'urf diartikan sebagai sesuatu kebiasaan yang berlaku dalam masyarakat baik berupa perbuatan yang berlaku umum atau lafadz yang memiliki makna tidak asing dalam masyarakat. Menurut Mustafa Ahmad alZarqa 'urf merupakan suatu hal yang disepakati dan menjadi kebiasaan yang

\footnotetext{
${ }^{7}$ Satria Efendi, Ushul Fiqh (Jakarta: Kencana, 2005), 364-365..

${ }^{8}$ Faiz Zainuddin, 'Konsep Islam Tentang Adat', LISAN AL-HAL: Jurnal Pengembangan Pemikiran Dan

Kebudayaan, Vol.12. No.1 (2018), 392.

9 Satria Efendi, Ushul Fiqh..., 364-365.

${ }^{10}$ Abdul Aziz Dahlan, Ensiklopedia Hukum Islam (Jakarta: Ichtiar Baru Van Hoeve, 2006), 1877.
} 
berlaku dalam masyarakat. ${ }^{11}$ Menurut ulama ushul fiqh 'urf memiliki pengertian

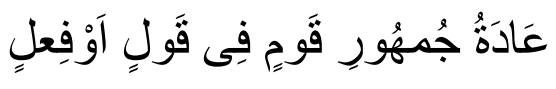

Artinya: "Kebiasaan mayoritas kaum baik dalam perbuatan maupun perkataan." 12

Menurut Rahman Dahlan 'urf menurut istilah diartikan sebagai berikut:

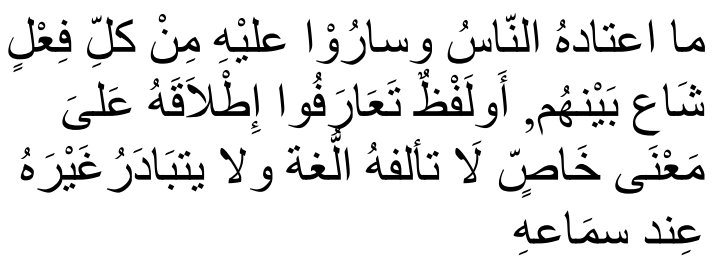

Artinya: "Sesuatu yang menjadi kebiasaan manusia dan mereka mengikutinya dalam bentuk setiap perbuatan yang terkenal diantara mereka ataupun suatu kata yang biasa mereka kenal dengan pengertian tertentu bukan pengertian etimologi dan ketika mendengar kata itu mereka tidak memahaminya dalam pengertian lain." 13

Dari pengertian diatas, dapat disimpulkan tidak semua adat kebiasaan dapat dijadikan menjadi sumber hukum islam. Dalam hal ini harus diperhatikan hanya kebiasaan baik berupa perkataan maupun perbuatan baik yang tidak bertentangan dengan ajaran islam serta memiliki nilai maslahat yang dijadikan 'urf.' ${ }^{14}$

\section{Dasar Hukum 'urf}

'Urf (kebiasaan) dapat menjadi hakim atau suatu undang-undang yang

\footnotetext{
${ }^{11}$ Nurul Hakim, 'KONFLIK ANTARA AL-'URF (HUKUM ADAT) DAN HUKUM ISLAM DI INDONESIA', Jurnal EduTech, Vol.3. No.2 (2017), 55.

12 Totok Jumantoro dan Samsul Munir Amin, Kamus Ilmu Ushul Fiqih...,334.

${ }^{13}$ Abd. Rahman Dahlan, Ushul Fiqh (Jakarta: Amzah, 2010), 209.

${ }^{14}$ Alaiddin Koto, Ilmu Figh Dan Ushul Fiqh (Jakarta: Rajawali Pers, 2011), 110.
}

mengatur masyarakat apabila dalam kehidupan sosial masyarakat tidak memiliki peraturan, kebiasaan ini telah berlaku sejak zaman dahulu dimana 'urf menjadi hakim dalam kehidupan manusia. ${ }^{15}$ Para ulama menjadikan 'urf sebagai landasan hukum berdasarkan:

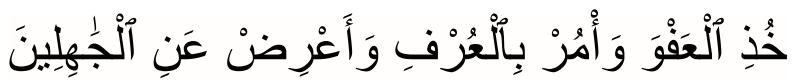
Artinya : “jadilah Engkau Pema'af dan suruhlah orang mengerjakan yang ma'ruf, serta berpalinglah dari pada orang-orang yang bodoh." (QS. Al-A'raf ayat 199) ${ }^{16}$

Dalam firman Allah surat Al-A'raf ayat 199 memerintahkan kepada umat muslim agar melakukan hal baik (ma'ruf) yang akan menjadi kebiasaan baik dan tidak bertentangan dengan tabiat manusia yang benar. ${ }^{17}$ Menurut Ibn 'Abidin yang dikutip oleh Rizal Mumazziq dalam ayat tersebut, Allah memerintahkan kepada Rasulullah Saw. agar umatnya mengikuti tradisinya. ${ }^{18}$ Karena apa yang dinilai baik maka hal tersebut baik dalam pandangan Allah, sebagaimana sabda Rasulullah Saw berikut ini:

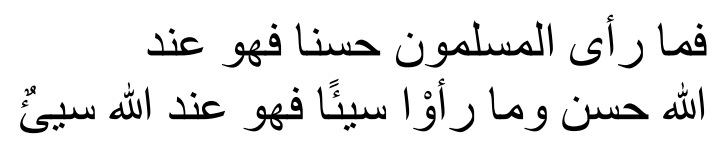

Artinya: "Maka apa yang dilihat oleh kaum muslimin satu kebaikan, maka disisi Allah adalah baikdan apa yang mereka pandang buruk maka apa yang disisi Allah juga buruk." (HR. Imam Ahmad-3418). ${ }^{19}$

${ }^{15}$ Nurul Hakim, "Konflik antara Al- 'URF (Hukum Adat) dan Hukum Islam di Indonesia..., 57.

${ }^{16}$ Depag RI, Depag RI, Al-Qur'an Dan Terjemah Indonesia (Jakarta: Sari Agung, 2002), 323.

17 Abd. Rahman Dahlan, Ushul Fiqh..., 212.

${ }^{18}$ Rijal Mumazziq Zionis, 'Posisi Al- ' Urf Dalam Struktur Bangunan', Jurnal Falasifa, Vol. 2. No.2 (2011), 134.

${ }^{19}$ Musnad Ahmad, Kutubut Tis'ah Kitab Nomor 3418. 
Dalam sabda Rasulullah tersebut yang disampaikan dari Abdullah bin Mas'ud mengenai kebiasaan-kebiasaan baik yang berlaku dalam masyarakat dan sejalan dengan syariat Islam merupakan hal yang baik dalam pandangan Allah, kemudian segala hal yang bertentangan dengan kebiasaan yang dinilai baik oleh masyarakat serta melahirkan kesulitan dan kesempitan dalam kehidupan sehari-hari maka kebiasaan tersebut buruk dalam pandangan Allah. ${ }^{20}$

Adanya pengembangan hukum Islam berupa 'urf (kebiasaan) menunjukkan bahwa Allah ingin memudahkan manusia dalam menjalankan kehidupan sesuai yang belum dijelaskan rinci dalam Al-Qur'an dan Hadis, sebagaimana dalam firman Allah surat Al-Maidah ayat 6:

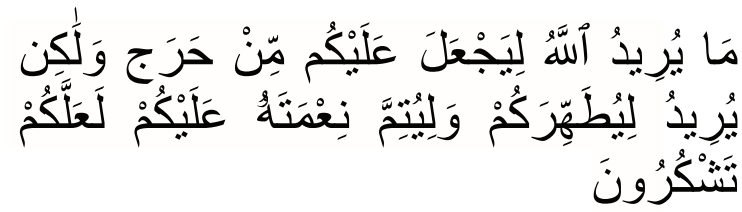

Artinya: "Allah tidak hendak menyulitkan kamu, tetapi Dia hendak membersihkan kamu dan menyempurnakan nikmat-Nya bagimu, supaya kamu bersyukur." (QS. Al-Maidah : 6). ${ }^{21}$

Para ulama sepakat bahwa 'urf dapat dijadikan dasar hujjah selama tidak bertentangan dengan syara'. Ulama Hanafiyah menggunakan istihsan al-'urf dalam berijtihad, yakni istihsan yang disandarkan dengan 'urf. Ulama Malikiyah menjadikan 'urf sebagai dasar dalam menetapkan hukum di kalangan ahli Madinah. Kemudian, ulama Syafi'iyah menggunakan 'urf dalam pendapat lama (qaul qadim) ketika Imam Syafi'i berada

20 Abd. Rahman Dahlan, Ushul Fiqh..., 212-213.

21 Depag RI, Al-Qur'an dan Terjemah Indonesia..., 195. di Irak dan pendapat baru (qaul jadid) ketika di Mesir. ${ }^{22}$

Para ulama sepakat hanya 'urf shahih yang dapat diterima sebagai landasan hukum dan menolak 'urf fasid untuk menjadi landasan hukum. Mengenai hal ini ulama merumuskan kaidah fiqhiyah mengenai ' $u r f$, berikut beberapa kaidah :

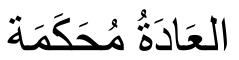

Artinya: "Adat kebiasaan dapat dijadikan hukum"

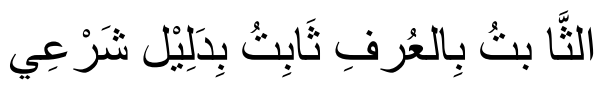

Artinya : "Yang berlaku berdasarkan 'urf seperti berlaku berdasarkan dalil syara'."

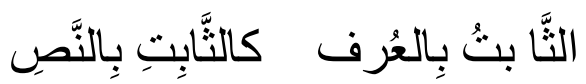

Artinya: "Yang berlaku berdasarkan 'urf seperti berlaku berdasarkan nash."

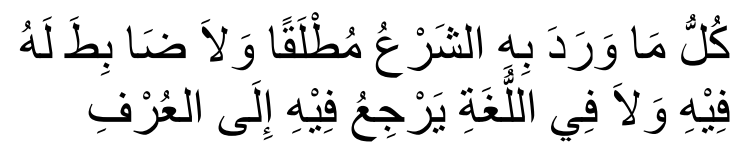

Artinya: "Semua ketentuan syara' yang bersifat mutlak dan tidak ada pembatasan di dalamnya, bahkan juga tidak ada pembatasan dari segi kebahasaan, maka pemberlakuannya dirujukan kepada 'urf." 23

Kemudian, ketika 'urf bertentangan dengan nass yang bersifat khusus sampai menggugurkan hukum dalam nass, maka 'urf tidak dapat dijadikan sebagai sumber hukum. Misalnya 'urf yang pernah berlaku di bangsa Arab sebelum Islam datang yaitu seorang laki-laki dapat menceraikan dan menikahi kembali wanita sesuka hati. Kemudian, setelah datangnya Islam terdapat hukum iddah (masa tunggu setelah diceraikan suaminya).

${ }^{22}$ Amir Syarifuddin, , Ushul Fiqh Jilid 2 (2008), 423. (Jakarta: Kencana, 2008), 423.

23 Abd. Rahman Dahlan, Ushul Fiqh..., 213. 
Ketika 'urf bertentangan dengan nass yang bersifat umum, menurut Mushtafa Ahmad az-Zarqa, ketika 'urf bertentangan dengan dalil umum, maka perlu membedakan antara 'urf amali dan 'urf lafzhi. Kemudian memahami redaksi dalil dengan 'urf lafzhi yang berlaku, kecuali ketika terdapat indikator yang menujukkan pembeda antara redaksi dalil dan 'urf maka sudah jelas antara 'urf dan dalil umum memiliki makna berbeda. Misalnya penggunaan kata walad biasanya diartikan anak laki-laki, akan tetapi dalam surat an-Nisa ayat 11 terdapat indikator lain yang menunjukkan makna walad adalah anak laki-laki dan perempuan. ${ }^{24}$

$$
\text { يُوِِيكُمُ ألسَّهُ فِحَ أَوْلَدِكُمْ }
$$

Artinya: "Allah mensyari'atkan bagimu tentang (pembagian pusaka untuk) anakanakmu." (QS. An-Nisa : 11)

Menurut $\mathrm{Abu}$ Yusuf, ketika illat berasal dari 'urf amali maka hukumnya mengikuti keberlakuan 'urf amali dalam masyarakat, apabila illat ('urf amali) telah hilang atau tidak berlaku lagi dalam masyarakat maka hukumnya berubah. Misalnya, hadis tentang diamnya seorang wanita adalah persetujuan.

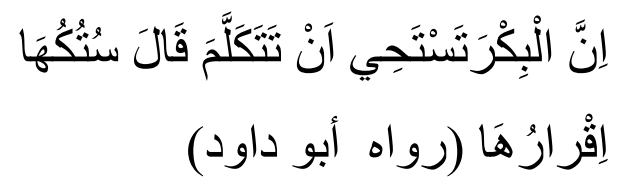

Artinya: "sesungguhnya seorang gadis akan merasa malu untuk berbicara. Beliau berkata, diamnya adalah persetujuanya. (HR. Abu Dawud). ${ }^{25}$

Dikisahkan pada masa tersebut, mayoritas wanita ketika ditanya kesiapan

\footnotetext{
${ }^{24}$ Sucipto, "Urf Sebagai Metode Dan Sumber

Penemuan Hukum Islam', Asas, Vol. 7. No. 1 (2015), 25-40.

${ }^{25}$ Sunan Abu Daud, Hadis Sunan Abu Dawud.
}

untuk menikah dengan seorang laki-laki mereka diam, pada masa tersebut diamnya wanita tersebut diartikan sebagai persetujuannya untuk menerima menikah dengan laki-laki tersebut. Akan tetapi, pada zaman sekarang ' $u r f$ tersebut tidak dapat dijadikan sebagai acuan persetujuan menerima menikah karena 'urf telah berubah sampai wanita mengucapkan kesiapannya. $^{26}$

\section{Jenis-Jenis 'Urf (Kebiasaan)}

Dalam hal ini, Ulama Ushul Fiqh membagi 'urf menjadi tiga macam, yaitu (1) dari segi objeknya; (2) dari segi cangkupan 'urf ; (3) dari segi keabsahan 'urf, berikut penjelasnnya:

1. Segi objeknya, 'urf dibagi menjadi dua macam, yaitu 'urf lafzi dan 'urf amali, berikut penjelasannya:

a) 'Urf lafzi (العرف التلفظي)

'Urf lafzi merupakan suatu kebiasaan masyarakat dalam menggunakan suatu ungkapan. Contohnya penjual daging yang menjual berbagai macam daging, kemudian ketika pembeli mengatakan "saya beli daging satu kilogram," tanpa bertanya kepada pembeli, penjual langsung mengambilkan daging sapi, meskipun kata daging mencakup semua daging yang dijua, tapi kata daging sudah menjadi kebiasaan masyarakat memiliki makna daging sapi. $^{27}$

b) 'Urf amali (العرف العمل)

'Urf amali merupakan suatu kebiasaan amal atau pekerjaan yang dikenal masyarakat. ${ }^{28}$ Contohnya ketika sifulan melakukan transaksi

${ }^{26}$ Sucipto, "Urf Sebagai Metode Dan Sumber.., 25-40.

27 Totok Jumantoro dan Samsul Munir Amin, Kamus Ilmu Ushul Fiqih..., 338.

${ }^{28}$ A.Syafi'i Karim, Ushul Fiqih (Bandung: Pustaka Setia, 2006), 85 . 
jual beli baju tanpa menyampaikan ijab dan qabul, jual beli tersebut diperbolehkan karena telah menjadi kebiasaan di masyarakat ketika seseorang melakukan pembayaran sejumlah harga barang yang telah disepakati antara kedua belah pihak maka dianggap telah terjadi ijab dan qabul antara penjual dan pembeli. ${ }^{29}$ Contoh lain kebiasaan yang sering terjadi di masyarakat, kebiasaan memakai sandal teman akrab tanpa ucapan saya pinjam, hal tersebut tidak dianggap mencuri. ${ }^{30}$

2. Segi cangkupannya, 'urf dibagi menjadi dua macam yaitu 'urf al-'am dan 'urf al-khas. Berikut penjelasannya:

a) 'Urfal-'am (العرف العام)

'Urf al-'am merupakan kebiasaan yang berlaku pada suatu tempat, masa dan keadaan yang berlaku luas dikalangan masyarakat. Contohnya membayar ongkos Gojek, kereta KAI atau kendaraan umum lainnya dengan harga tertentu yang dibatasi oleh jarak tempuh maksimal, jadi meskipun jarak tempuh hanya 1 $\mathrm{Km}$ tetap terhitung $5 \mathrm{Km}$ karena 5 $\mathrm{Km}$ menjadi patokan jarak maksimum. ${ }^{31}$

Contoh lainnya, biaya naik kereta Surabaya - Lumajang dan Surabaya-Jember ditarif dengan harga yang sama Rp. 29.000 padahal jarak tempuhnya berbeda, tetapi sudah menjadi kebiasaan di masyarakat bahwa KAI membatasi jarak tempuh maksimal berada di kota Jember.

b) 'Urfal-khas (العرف الخاص)

${ }^{29}$ Abd. Rauf, 'Kedudukan Hukum Adat Dan Hukum Islam', Tahkim, Vol.9. No.1 (2013), 20-34.

30 Totok Jumantoro dan Samsul Munir Amin, Kamus Ilmu Ushul Fiqih..., 336.

31 Abd Rahman Dahlan, Ushul Fiqh..., 210.
'Urf al-khas merupakan kebiasaan yang berlaku di daerah tertentu dan dalam masyarakat tertentu, menurut Mustafa Ahmad az-Zahra 'urf khas terus berkembang sesuai dengan perubahan situasi dan kondisi. Misalnya, kebiasaan yang terjadi dikalangan pengacara hukum seorang klien harus membayar dahulu jasa pembelaan hukum. ${ }^{32}$

3. Segi keabsahannya, dibagi menjadi dua macam yaitu 'urf shahih dan 'urf fasid. Berikut penjelasannya:

a) 'Urf shahih (العرف الصحيح)

'Urf shahih merupakan kebiasaan yang berlaku dalam masyarakat yang tidak bertentangan dengan nash (al-Qur'an dan Hadis) dan menciptakan maslahah, ${ }^{33}$ tidak menghukumi haram suatu yang halal dan tidak membatalkan sesuatu perkara wajib. ${ }^{34}$

Menurut Imam al-Syatibi dan Ibn Qayyim al-Jauziyah 'urf dapat dijadikan sebagai dalil ketika tidak ada nash yang menjelaskan masalah tersebut, misalnya ketika terjadi perselisihan dalam sewa-menyewa atau kerjasama antara pemilik sawah dan penggarap, maka penyelesaian masalah tersebut dapat disesuaikan dengan kebiasaan yang berlaku dalam masyarakat. Akan tetapi, ketika kebiasaan masyarakat bertentangan dengan nash seperti adanya riba, suap-menyuap maka kebiasaan tersebut tidak dapat dijadikan ' $u r f .{ }^{35}$

32 Abdul Aziz Dahlan, Ensiklopedia Hukum Islam..., 1877.

33 Totok Jumantoro dan Samsul Munir Amin, Kamus Ilmu Ushul Fiqih..., 339.

${ }^{34}$ Abdul Wahhab Khallaf, Ilmu Ushul Al-Fiqh (Kairo: Dar al-Qalam, t.t.), 89.

35 Toha Andiko, Ilmu Qowa'id Fiqhiyyah Panduan Praktis Dalam Memproses Problematika Hukum Islam Kontemporer (Yogyakarta: Teras, 2011), 146. 
Para ulama menyepakati al-'urf shahih menjadi kebiasaan yang wajib dipelihara dan diikuti. Seorang mujtahid wajib menggunakan 'urf shahih ketika mengali hukumhukum syariat dan seorang hakim harus memperhatikan 'urf shahih ketika memutuskan perkara di pengadilan. ${ }^{36}$

Abdul Karim Zaydan menerangkan bahwa Nabi Saw. mementingkan suatu kemaslahatan masyarakat kebiasaan ('urf) shahih. Contohnya, perhitungan 'ashabah dalam perwalian dan waris merupakan kebiasaan masyarakat pra-Islam yang menjadi syariat islam. ${ }^{37}$

b) 'Urffasid (العرف الفاسد)

'Urf fasid merupakan kebiasaan buruk yang tidak dapat diterima menjadi hukum karena bertentangan dengan nass (Al-Qur'an dan Hadis). urf fasid tidak dapat dipelihara untuk menjadi kebiasaan, karena adanya kebiasaan yang bertentangan dengan syariat akan mengakibatkan rusaknya fondasi hukum Islam dan belum tentun mengandung maslahah, apabila ada maslahah pasti hanya bersifat subjektif, temporal (sesaat), parsial atau local particular. ${ }^{38}$

Misalnya, kebiasaan adanya sesajian di tempat keramat yang bertentangan dengan ajaran tauhid, kemudian kebiasaan menghalalkan riba dikalangan pedangan dengan meminjamkan uang antar pedangan dan ada tambahan bunga, kebiasaan tersebut tidak dapat dijadikan 'urf karena berlawanan dengan firman

${ }^{36}$ Abdul Haqm dkk., Formulasi Nalar Fiqh (Surabaya: Khalista, 2006), 293.

${ }^{37}$ Abdul Karim Zaydan, Al-Wajiz Fi Ushul Al-Fiqh (Beirut: Mu'assasah al-Risalah, 2001), 253.

38 Abdul Haqm dkk, Formulasi Nalar Fiqh..., 293.
Allah surat Al-Baqarah ayat 275 "Allah menghalalkan jual beli dan mengharamkan riba". 39

\section{Syarat Adat Kebiasaan menjadi ' $U \boldsymbol{r f}$}

'Urf merupakan hukum yang berasal dari non-ilahiah yaitu berasal dari adat atau kebiasaaan yang dilakukan berulang-ulang, dalam hal ini para ulama ushul fiqih memberikan syarat agar sebuah adat atau kebiasaan dapat dijadikan sebagai sumber hukum, adapun syaratnya sebagai berikut:

1. Adat kebiasaan berlaku secara umum dalam mayoritas kasus yang terjadi di masyarakat dan dapat berlaku pada mayoritas masyarakat. ${ }^{40}$

2. Adat kebiasaan telah memasyarakat sebelum adanya kasus yang dicari hukumnya, hal ini sesuai dengan kaidah usuliyah yang berbunyi:

لاعبرة للعرف الطارى "urf yang datang
Artinya: “'urf
kemudian tidak dapat dijadikan
sandaran hukum terhadap kasus
yang telah lama.".41

3. Adat kebiasaan tidak bertentangan dengan suatu ungakapan jelas dalam transaksi. Ketika penjual dan pembeli memberikan ungkapan secara jelas ketika melakukan transaksi maka 'urf yang berlaku gugur, misalnya ketika si fulan membeli kulkas, kebiasaannya penjual yang akan mengantarkan barang dagangannya ke rumah pembeli, akan tetapi kebiasaan pengantaran barang oleh penjual

39 Totok Jumantoro dan Samsul Munir Amin, Kamus Ilmu Ushul Fiqih..., 337.

${ }^{40}$ Djazuli, Ilmu Fiqh Penggalian, Perkembangan Dan Penerapan Hukum Islam Edisi Revisi (Jakarta: Kencana, 2005), 89.

41 Totok Jumantoro dan Samsul Munir Amin, Kamus Ilmu Ushul Fiqih..., 335. 
gugur ketika si fulan akan membawa kulkasnya sendiri. ${ }^{42}$

4. Adat kebiasaan tidak bertentangan dengan nash (Al-Qur'an dan Hadis) dan tidak ada dalil khusus yang menjelaskan masalah tersebut.

5. Tidak mengakibatkan kemafsadatan, kesempitan, dan kesulitan. ${ }^{43}$

\section{HASIL DAN PEMBAHASAN}

Pada tahun 2016 pihal LP POM MUI Jatim menolak pengajuan sertifikasi halal MUI seorang manajer mie setan saudara Runiar pada produknya bernama "mie setan". ${ }^{44}$ Penolakan ini terjadi sebelum tahap audit dan penelitian produk, menurut staf LP POM MUI nama produk yang memiliki nama atau simbol setan harus dirubah menjadi nama yang baik terlebih dahulu, karena nama setan tidak sesuai dengan Surat Keputusan SK 46/Dir/LPPOM MUI/XII/14 yang mengatur mengenai nama produk yang tidak disertifikasi, antara lain:

“(1) Nama produk yang mengadung nama minuman keras, contohnya rootbeer, es krim rasa rhum raisin, bir 0\% alkohol; (2) Nama produk yang mengandung nama babi dan anjing serta turunannya, seperti babi panggang, babi goreng, beef bacon, hamburger, hotdog; (3) Nama produk yang mengandung nama setan, seperti rawon setan, es pocong, mie ayam kuntilanak; (4) Nama produk yang mengarah kepada halhal yang menimbulkan kekufuran dan kebatilan, seperti coklat valentine, biskuit natal, mie goring Xi Fa Cai; (5) Nama produk yang mengandung kata-kata yang berkonotasi erotis, fulgar dan atau porno."
Dalam Surat Keputusan tersebut, terdapat catatan yang perlu diperhatikan, antara lain:

“(a) Poin-poin di atas tidak berlaku untuk produk yang telah mentradisi ('urf), dikenal secara luas dan dipastikan tidak mengandung unsur-unsur yang diharamkan seperti bir pletok, bakso, bakmi, bakwan, bakpia dan bakpao; (b) Merk atau brand produk yang mengandung produk haram lainnya dibolehkan untuk disertifikasi, misalnya merk garuda, kubra, bear, crocodile, cap badak; (c) Nama produk yang mengandung kata sexy dan sensual boleh disertifikasi, contohnya lipstick sexy pinky, lotion sensual amber, spa sensual."45

Dari catatan surat keputusan poin (a) menunjukkan bahwa pelarangan pada Surat Keputusan SK 46/Dir/LPPOM $\mathrm{MUI} / \mathrm{XII} / 14$ yang mengatur mengenai nama produk yang tidak disertifikasi tidak berlaku pada produk yang telah mentradisi ('urf) yang dikenal luas dan tidak mengandung unsur yang diharamkan. Adapun salah satu produk yang dikenal umum dan digemari para pecinta pedas di kota Surabaya adalah produk Mie setan, simbol dan nama setan menunjukkan bahwa makan tersebut pedas. Berikut gambar produk tersebut :

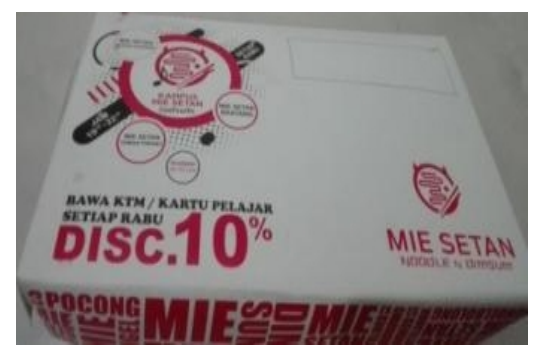

Gambar. Produk Mie Setan

\footnotetext{
${ }^{42}$ Sucipto, "Urf Sebagai Metode dan Sumber Pnemuan Hukum Islam,”..., 32.

43 Djazuli, Ilmu Fiqh Penggalian, Perkembangan dan Penerapan Hukum Islam..., 89.

44 Runiar, wawancara, (Surabaya, 2018).
}

45 Surat Keputusan Pengkajian Pangan, Obat-Obatan dan Kosmetik Majelis Ulama Indonesi Tentang Ketentuan Penulisan Nama Produk dan Bentuk Produk Nomor: SK 46/Dir/LPPOM MUI/XII/14. 
Bisnis mie setan, namanya yang unik dan membuat orang penasaran telah menyebar diberbagai kota yaitu di kota Surabaya, Malang, Jombang, Bali, dan lain-lain. Produk mie setan hingga saat ini masih ada di berbagai kota. Selanjutnya, dari saran konsumen dan pemilik saham Mie setan yaitu Bapak Runiar menginginkan adanya label Halal MUI pada produk Mie setan agar memberikan jaminan makanan halal dan bisnis menjadi lebih barakah. Akan tetapi pihak LPPOM MUI Jatim menolak karena nama dan lambang produk setan. Dari hasil wawancara kepada bapak Sugijanto selaku direktur LP POM MUI Jatim menyatakan bahwa nama setan pada suatu makanan akan mengarah pada nama musuhnya Allah atau nama yang diharamkan oleh Allah, seperti setan, kuntianak, babi, bir, kafir, munafik, dan lain sebagainya. Apabila dalam pengajuan sertifikasi halal MUI produk memiliki nama yang menjadi musuhnya Allah maka pihak LP POM MUI Jatim akan menolak pengajuan tersebut. ${ }^{46}$

Meskipun dalam masyarakat penggunaan nama setan telah menjadi kebiasaan di masyarakat umum memiliki makna makanan pedas, hal ini tidak dapat dimasukkan dalam kategori kebiasaan ungkapan dalam masyarakat ('urf lafzi) yang mendapatkan sertifikasi halal MUI, karena berdasarkan keabsahannya penggunaan nama setan pada produk termasuk dalam 'urf fasid, dikarenakan nama setan merupakan nama musuhnya Allah yang harus dihindari bukan malah menjadikan sebagai sesuatu yang menyenangkan dan sampai menjadi idola.

Apabila seseorang mengidolakan makanan dengan nama musuhnya Allah sepeti mie setan, rawon setan, bakso kafir dikhawatirkan akan mempengaruhi mindset dan mengakibatkan sesorang

\footnotetext{
${ }^{46}$ Sugijanto, Wawancara (Surabaya, 2019).
}

sering menyebut hal yang menjadi kesenangannya dan dikhawatirkan dapat menjauhkan mengingat Allah karena sering menyebut nama setan meskipun tujuannya hanya makan mie setan. Hal ini sebagaimana dalam firman Allah Surah Al-Baqarah ayat 168:

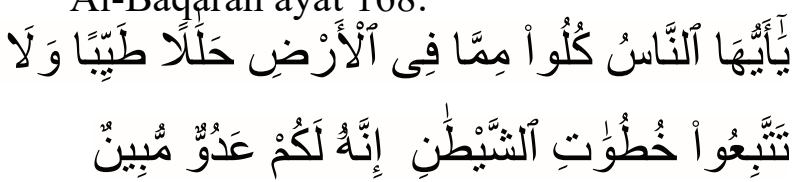

Artinya: "Hai sekalian manusia, makanlah yang halal lagi baik dari apa yang terdapat di bumi, dan janganlah kamu mengikuti langkah-langkah syaitan; karena Sesungguhnya syaitan itu adalah musuh yang nyata bagimu." 47

Menurut direktur LP POM MUI Jatim, bapak Sugijanto memberikan penjelasan bahwa sebagai seorang muslim kita dilarang mengikuti langkah-langkah syaitan baik suatu ajaran syaitan yang nampak maupun tidak nampak. Penolakan sertifikasi label halal MUI pada produk mie setan bertujuan agar tidak semakin menyebar penggunaan nama aneh atau nama yang menjadi musuhnya Allah seperti nama setan semakin menyebar dan memunculkan penggunaan nama aneh lainnya seperti munafik, kafir, dan lainlain. oleh karena itu menurut pihak LP POM MUI Jatim produk mie setan dari segi namanya berlawanan dengan ajaran tauhid yang diajarkan Islam. Dalam mejalani hidup ini, sorang hamba Allah harus melindungi aqidah, pola pikir, makanannya, keturunannya dan melindungi harga dirinya. ${ }^{48}$

Dari penjelasan direktur LP POM MUI Jatim tersebut, maka penggunaan kata setan pada produk mie setan meskipun telah dikenal luas bermakna makanan pedas tetap tidak memenuhi syarat-syarat adat yang dapat dijadikan

${ }^{47}$ Depag RI, Al-Qur'an dan Terjemah Indonesia, 46.

${ }^{48}$ Sugijanto, Wawancara (Surabaya, 2019). 
'urf karena mengakibatkan kemafsadatan, hal ini sesuai dengan kaidah fiqh :

\begin{tabular}{lr} 
& \multicolumn{2}{c}{ harus } \\
$\begin{array}{l}\text { Artinya: } \\
\text { dihilangkan."Kemudharatan }\end{array}$ & \\
Penolakan pengajuan & sertifikasi
\end{tabular} label halal MUI pada produk mie setan bukan berarti mie setan dikategorikan sebagai makanan tidak halal, akan tetapi konsumen tidak mendapatkan jaminan kehalalan dari LP POM MUI Jatim produk mulai dari alat dan bahan, proses pengelolaan sampai proses pengemasan. Dari permasalah tersebut, maka masyarakat harus berhati-hati dan selektif terhadap produk yang belum mendapatkan label halal MUI.

Pemberian nama bukan hanya sekedar nama, akan tetapi nama akan memberikan kesan yang mendalam dan akan membekas dalam hati serta mempengaruhi pola kehidupan seseorang. Dalam Surat Keputusan SK 46/Dir/LPPOM MUI/XII/14 terdapat pengecualian terhadap produk yang menjadi kebiasaan ('urf) yang dikenal luas serta tidak mengandung unsur yang diharamkan seperti bir pletok, bakso, bakmi, bakwan, bakpia dan bakpao.

Secara umum, bir memiliki arti minuman beralkohol yang menyebabkan seorang mabuk dengan tanda penurunan kemampuan mental dan fisik pada pengkonsumsi. Penggunaan kata bir pada bir pletok telah menjadi tradisi turun menurun orang betawi dan diterima oleh masyarakat luas bahwa makna dari bir pletok adalah minuman jahe yang menghangatkan bukan minuman mengandung alkhohol.

Akan tetapi penggunaan bir pada suatu produk tidak boleh sembarang

${ }^{49}$ Khairuddin Habziz, Simpel Dan Mudah Menguasai 175 Kaidah Fiqih (Situbondo: Tanwirul Afkar, 2019), 37. digunakan, misalnya menggunaan nama bir zero alkohol. Meskipun bir zero alkohol memiliki arti minuman tanpa alkohol tidak dapat dimasukkan dalam 'urf lafzi yang dapat diterima masyarakat. Pelarangan tersebut bertujuan agar tidak membiasakan menggunakan nama yang tidak disukai Allah. ${ }^{50}$

Seperti halnya penolakan sertifikasi label halal MUI pada produk mie setan bertujuan agar tidak membiasakan dan tidak semakin berkembangnya produk dengan nama yang menjadi musuhnya Allah akan mengajukan sertifikasi label halal MUI dan hal ini akan berdampak luas dan merusak moral dan pikiran manusia sebagai hamba Allah.

Kemudian, penggunaan nama produk Bakso, bakpia, bakpao, bakwan merupakan turunan dari kata bak yang memiliki arti daging babi. ${ }^{51}$ Akan tetapi nama bakso bakpia, bakpau, bakwan telah menjadi tradisi yang sudah dikenal oleh masyarakat umum bukan makanan yang berasal dari bahan babi, misalnya ketika seseorang berkata makan bakso maka tidak ada makna lain selain makanan yang terbuat dari daging sapi bercampur dengan mie. Sebagai umat muslim kita harus berhati-hati dalam mengonsumsi makanan. ${ }^{52}$

Selanjutnya, dalam Fatwa MUI Nomor 4 Tahun 2003 tentang Standarisasi Fatwa halal pada bagian keempat LP POM MUI mengatur tentang pemberian nama yang sesuai dengan standart MUI, yaitu:

“(1) Tidak boleh mengkonsumsi dan menggunakan nama dan atau symbol-

\footnotetext{
50 Sugijanto, Wawancara (Surabaya, 2019).

${ }^{51}$ Mansyur Faqih, 'Untuk Muslim, Ini Istilah Daging Babi Yang Perlu Diwaspadai | Republika Online', Republika, $2015<$ https://republika.co.id/berita/duniaislam/islam-nusantara/15/01/28/niojk4-untuk-muslimini-istilah-daging-babi-yang-perlu-diwaspadai $>$ [accessed 8 February 2021].

52 Sugijanto, Wawancara (Surabaya, 2019).
} 
simbol makanan atau minuman yang mengarah kepada kekufuran dan kebatilan; (2) Tidak boleh mengkonsumsi makanan atau minuman yang mengarah kepada nama-nama benda atau binatang yang diharamkan terutama babi dan khamar, kecuali yang telah mentradisi ('urf) dan dipastikan tidak mengandung unsur-unsur yang diharamkan, seperti nama bakso, bakpia, dan bakpao; (3) Tidak boleh mengkonsumsi dan menggunakan bahan campuran bagi komponen makanan atau minuman yang menimbulkan rasa atau aroma (flavour) benda-benda atau binatang yang diharamkan seperti mie instan rasa babi, bacon flavour, dan lainlain; (4) Tidak boleh mengonsumsi makanan atau minuman yang menggunakan nama-nama makanan atau minuman yang diharamkan seperti whisky, brandy, beer, dan lain-lain." 53

"Catatan: perlu adanya konsideran yang jelas dalam fatwa ini, pengertian tidak boleh bertujuan untuk berhati-hati (tahdzir), siaga (tanfir), menakuti (tarhib) bukan berarti mengharamkan yang halal atau menghalalkan yang haram."

Jadi produk mie setan dalam pandangan Fatwa MUI Nomor 4 Tahun 2003 tidak sesuai dengan standart MUI, meskipun pelaggan mie setan membeli produk mie setan tidak ada tujuan untuk kufur atau melakukan kebatilan, sebagaimana mengamalkan kaidah fiqh :

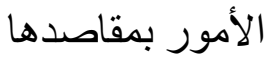

Artinya: "Segala sesuatu tergantung pada maqasid (tujuan)nya". 54

Akan tetapi penggunaan nama dan simbol setan pada suatu produk tidak boleh karena nama dan simbol setan mengarah kepada kekufuran dan kebatilan.

\footnotetext{
53 Fatwa MUI Nomor 4 Tahun 2003 Tentang Sttandarisasi Fatwa Halal..

54 Khairuddin Habziz, Simpel Dan Mudah Menguasai 175 Kaidah Fiqih..., 23.
}

Ketidakbolehan mengonsumsi atau menggunakan nama setan dalam Fatwa MUI Nomor 4 Tahun 2003 bukan berarti mengaharamkan suatu makanan, akan tetapi bertujuan untuk kehati-hatian, siaga dan menakuti sebagaimana tercantum dalam catatan Fatwa MUI Nomor 4 Tahun 2003.

\section{KESIMPULAN}

'Urf merupakan sumber hukum yang berasal dari adat kebiasaan di masyarakat yang tidak bertentangan dengan ajaran Islam dan dapat berlaku umum serta memberikan kemaslahatan. Tidak semua adat kebiasaan dapat dijadikan sebagai 'urf akan tetapi hanya 'urf shahih yang dapat dijadikan sebagai 'urf. Dalam aplikasinya, urf telah diamalkan oleh semua ulama fiqh terutama pada kalangan madzhab Hanafi, Maliki dan Syafi'i.

Pada produk bernama setan meskipun telah mentradisi ('urf lafzi) bermakna makanan pedas, menurut keabsahannya penggunaan nama setan termasuk 'urf fasid yang tidak dapat dijadikan sebagai 'urf shahih karena berlawanan dengan ajaran tauhid yang diajarkan Islam karena dikhawatirkan melupakan mengingat Allah dan tidak sesuai dengan Surat Keputusan No. 46/ Dir/ LPPOM MUI/ XII/ 14 mengenai nama produk yang tidak dapat disertifikasi dan tidak sesuai dengan Fatwa MUI Nomor 4 Tahun 2003 Tentang Standardisasi Fatwa halal mengenai penggunaan nama atau simbol yang mengarah pada kekufuran.

Tidak adanya label halal MUI pada produk mie setan bukan berarti mie setan termasuk dalam makanan terlarang akan tidak mendapatkan jaminan kehalalan produk dari LP POM MUI Jatim, sehingga umat muslim harus berhati hati dan selektif terhadap produk yang belum memiliki label halal MU 


\section{REFERENSI}

[1] Abdul Haqm dkk., 2006, Formulasi Nalar Fiqh, Surabaya: Khalista.

[2] Andiko, Toha, 2011, Ilmu Qowa'id Fiqhiyyah Panduan Praktis Dalam Memproses Problematika Hukum Islam Kontemporer, Yogyakarta: Teras.

[3] Dahlan, Abd. Rahman, 2010, Ushul Fiqh, Jakarta: Amzahj

[4] Dahlan, Abdul Aziz, 2006, Ensiklopedia Hukum Islam, Jakarta: Ichtiar Baru Van Hoeve.

[5] Djazuli, 2005, Ilmu Fiqh Penggalian, Perkembangan Dan Penerapan Hukum Islam Edisi Revisi, Jakarta: Kencana.

[6] Dkk, Ma'ruf Amin., 2011, Himpunan Fatwa Majelis Ulama Indonesia Sejak 1975, Jakarta: Erlangga.

[7] Efendi, Satria, 2005, Ushul Fiqh, Jakarta: Kencana.

[8] Faqih, Mansyur, 'Untuk Muslim, Ini Istilah Daging Babi Yang Perlu Diwaspadai | Republika Online', Republika, $2015<$ https://republika.co.id/berita/dunia-islam/islamnusantara/15/01/28/niojk4-untuk-muslim-ini-istilah-daging-babi-yang-perlu-diwaspadai $>$ [accessed 8 February 2021]

[9] Habziz, Khairuddin, 2019, Simpel Dan Mudah Menguasai 175 Kaidah Fiqih, Situbondo: Tanwirul Afkar.

[10] Hakim, Nurul, 2017, 'KONFLIK ANTARA AL-'URF (HUKUM ADAT) DAN HUKUM ISLAM DI INDONESIA', Jurnal EduTech, Vol. 3. No. 2.

[11] Jumantoro, Totok dan Samsul Munir Amin, 2005, Kamus Ilmu Ushul Fiqih, T.tp: Amzah

[12] Karim, A.Syafi'i, 2006, Ushul Fiqih,Bandung: Pustaka Setia.

[13] Khallaf, Abdul Wahhab, t.t, Ilmu Ushul Al-Fiqh, Kairo: Dar al-Qalam.

[14] Koto, Alaiddin, 2011, Ilmu FiqhDan Ushul Fiqh, Jakarta: Rajawali Pers

[15] Majelis Ulama Indonesia, 2014, 'Ketentuan Penulisan Nama Produk Dan Bentuk Produk'

[16] MUI, 2003, 'Standardisasi Fatwa Halal', Himpunan Fatwa MUI.

[17] Rauf, Abd., 2013, 'Kedudukan Hukum Adat Dan Hukum Islam', Tahkim, Vol.9. No.1, 2034

[18] RI, Depag, Depag RI, Al-Qur'an Dan Terjemah Indonesia, 2002, Jakarta: Sari Agung

[19] Sucipto, 2019, 'Urf Sebagai Metode Dan Sumber Penemuan Hukum Islam', Asas, 7.1, 2540

[20] Sugijanto, Wawancara (Surabaya, 2019)

[21] Syarifuddin, Amir, 2008, Ushul Fiqh Jilid 2, Jakarta: Kencana.

[22] — 1997, Ushul FIqh, Jakarta: Logos Wacana Ilmu.

[23] Zainuddin, Faiz, 2018, 'Konsep Islam Tentang Adat', LISAN AL-HAL: Jurnal Pengembangan Pemikiran Dan Kebudayaan, Vol. 12. No.1, 145-58.

[24] Zaydan, Abdul Karim, 2001, Al-Wajiz Fi Ushul Al-Fiqh, Beirut: Mu'assasah al-Risalah

[25] Zionis, Rijal Mumazziq, 2011, 'Posisi Al- 'Urf Dalam Struktur Bangunan', Jurnal Falasifa, Vol. 2. No.2, 131-50 